\title{
Cloning and characterization of two Argonaute genes in wheat (Triticum aestivum L.)
}

Fanrong Meng ${ }^{1}$, Haiying Jia ${ }^{1 \dagger}$, Na Ling ${ }^{1+}$, Yinlei Xue ${ }^{1 \dagger}$, Hao Liu ${ }^{1}$, Ketao Wang ${ }^{1}$, Jun Yin ${ }^{2,3}$ and Yongchun Li ${ }^{2,3^{*}}$

\begin{abstract}
Background: Argonaute proteins are key components of RNA interference (RNAi), playing important roles in RNA-directed gene silencing. Various classes of Argonaute genes have been identified from plants and might be involved in developmental regulation. However, little is known about these genes in wheat (Triticum aestivum).

Results: In this study, two full-length cDNAs of Argonaute were cloned from wheat, designated as TaAGO1b and TaAGO4. The cDNA of TaAGO1b is 3273 bp long and encodes 868 amino acids, with a predicted molecular weight of $\sim 97.78 \mathrm{kDa}$ and pl of 9.29. The 3157-bp TaAGO4 encodes 916 amino acids, with a molecular mass of $102.10 \mathrm{kDa}$ and pl of 9.12. Genomics analysis showed that TaAGO1b and TaAGO4 contain 20 and 18 introns, respectively. Protein structural analysis demonstrated that typical PAZ and PIWI domains were found in both TaAGO1b and TaAGO4. From the highly conserved PIWI domains, we detected conserved Asp-Asp-His (DDH) motifs that function as a catalytic triad and have critical roles during the process of sequence-specific cleavage in the RNAi machinery. Structural modelling indicated that both TaAGOs can fold to a specific $\alpha / \beta$ structure. Moreover, the three aligned DDH residues are spatially close to each other at the "slicer" site of the PIWI domain. Expression analysis indicated that both genes are ubiquitously expressed in vegetative and reproductive organs, including the root, stem, leaf, anther, ovule, and seed. However, they are differentially expressed in germinating endosperm tissues. We were interested to learn that the two TaAGOs are also differentially expressed in developing wheat plants and that their expression patterns are variously affected by vernalization treatment. Further investigation revealed that they can be induced by cold accumulation during vernalization.

Conclusions: Two putative wheat Argonaute genes, TaAGO1b and TaAGO4, were cloned. Phylogenetic analysis, prediction of conserved domains and catalytic motifs, and modelling of their protein structures suggested that they encode functional Argonaute proteins. Temporal and spatial expression analyses indicated that these genes are potentially involved in developmental regulation of wheat plants.
\end{abstract}

Keywords: Argonaute, Cloning, Development, Gene expression, Wheat (Triticum aestivum L.)

\section{Background}

The RNA interference pathways are well-known for their critical roles in post-transcriptional gene silencing, and in triggering chromatin modifications [1]. Genetic, biochemical, and structural studies have implicated Argonaute (AGO) proteins as the catalytic core of the RNAi effector complex RISC; the first AGO gene was identified in

\footnotetext{
* Correspondence: yongchunli71@yahoo.com.cn

${ }^{\dagger}$ Equal contributors

${ }^{2}$ National Engineering Research Centre for Wheat, Henan Agricultural University, Zhengzhou 450002, China

${ }^{3}$ State Key Laboratory Cultivation Base of Crop Physiological Ecology and Genetic Improvement in Henan Province, Henan Agricultural University, Zhengzhou 450002, China

Full list of author information is available at the end of the article
}

Arabidopsis thaliana [2,3]. Plant AGO proteins are highly conserved basic proteins (approximately $100 \mathrm{kDa}$ ) with typical structural domains or amino acid motifs. These include a C-terminal PIWI (P-element induced wimpy testis) domain with an RNase-H-like fold, a central PAZ (Piwi Argonaute and Zwille) domain that binds small RNAs through the 3 ' end of the target RNA, and a MID domain, located between the PAZ and the PIWI domains, which anchors the 5 phosphate end of small RNAs onto Argonaute proteins [4,5]. Based on both their phylogenetic relationships and their capacity to bind to small RNAs, one can sort these proteins into three groups: I, which is the AGO-like subfamily (similar to AGO1 of Arabidopsis thaliana) that bind to microRNAs (miRNAs)

\section{Biomed Central}


and small interfering RNAs (siRNAs); II, the PIWI-like subfamily (closely related to the PIWI protein of Drosophila melanogaster), members of which bind to PIWIinteracting RNAs (piRNAs); and III, the WAGO subfamily (Worm-specific Argonautes) that bind to secondary siRNAs [5-7].

AGO-small-RNA complexes can repress the transcription of genes, target mRNAs for site-specific cleavage or general degradation, or block mRNA translation into protein. Some evidence suggests that Argonaute proteins play crucial roles in RNA-directed gene silencing, as well as being involved in the developmental regulation of plants [8-10]. Through genomic annotation, 10 and 18 AGO genes have been identified from Arabidopsis thaliana and rice (Oryza sativa), respectively [4,11]. Although some of these AGO members have been characterized, most remain unexplored in plants.

Wheat (Triticum aestivum) is a globally important crop, accounting for $20 \%$ of the calories consumed by humans [12]. Research that focuses on mechanisms for developmental regulation at the molecular level is very important for accelerating the progress of wheat improvement. AGO proteins, acting as key components in RNA-directed gene-silencing mechanisms, play significant roles in developmental regulation $[9,10]$. However, little is known about such genes in wheat. Here, we cloned and characterized two wheat AGO genes and analyzed their temporal and spatial expression patterns. We also investigated their potential involvement in development-specific gene regulation.

\section{Results}

\section{Cloning of TaAGOs with full-length cDNA}

We performed a TBLASTX analysis in the NCBI EST (expressed sequence tag) database (http://www.ncbi.nlm. nih.gov/dbEST/) with two Arabidopsis Argonaute genes, AGO1 [GenBank: NM_179453] and AGO4 [GenBank: NM_128262]. Two groups of wheat ESTs proved to be highly homologous to Arabidopsis AGO1 and AGO4. Based on the conserved regions of their EST sequences, we designed specific primers (Additional file 1) for cloning the wheat Argonaute genes.

RT-PCR (reverse transcription-polymerase chain reaction) amplification was conducted with the primer combination of TaAGO1-1F and -1R. A 412-bp cDNA fragment (Figure 1-A) was cloned. To elongate the sequence of the wheat Argonaute gene, new primers were designed based on the cloned sequence and used in 5'and 3'-RACE (Rapid Amplification of cDNA Ends). Although 5'-RACE analysis was performed several times, no satisfactory results were obtained. Therefore, we selected a genome-walking strategy to clone that 5 region. First, the genomic fragment corresponding to the cDNA region (Figure 1-A) was cloned and genomewalking primers (Additional file 1) were designed based on the sequence. Three rounds of genome-walking (Figure 1, GW1-3) were then conducted to obtain the 3958-bp genomic DNA. Finally, the 5'-cDNA region (Figure 1-B) was deduced by assembling exons (http:// genes.mit.edu/GENSCAN.html). The 3'-cDNA fragment (Figure 1-C) was analyzed by 3'-RACE. The full-length

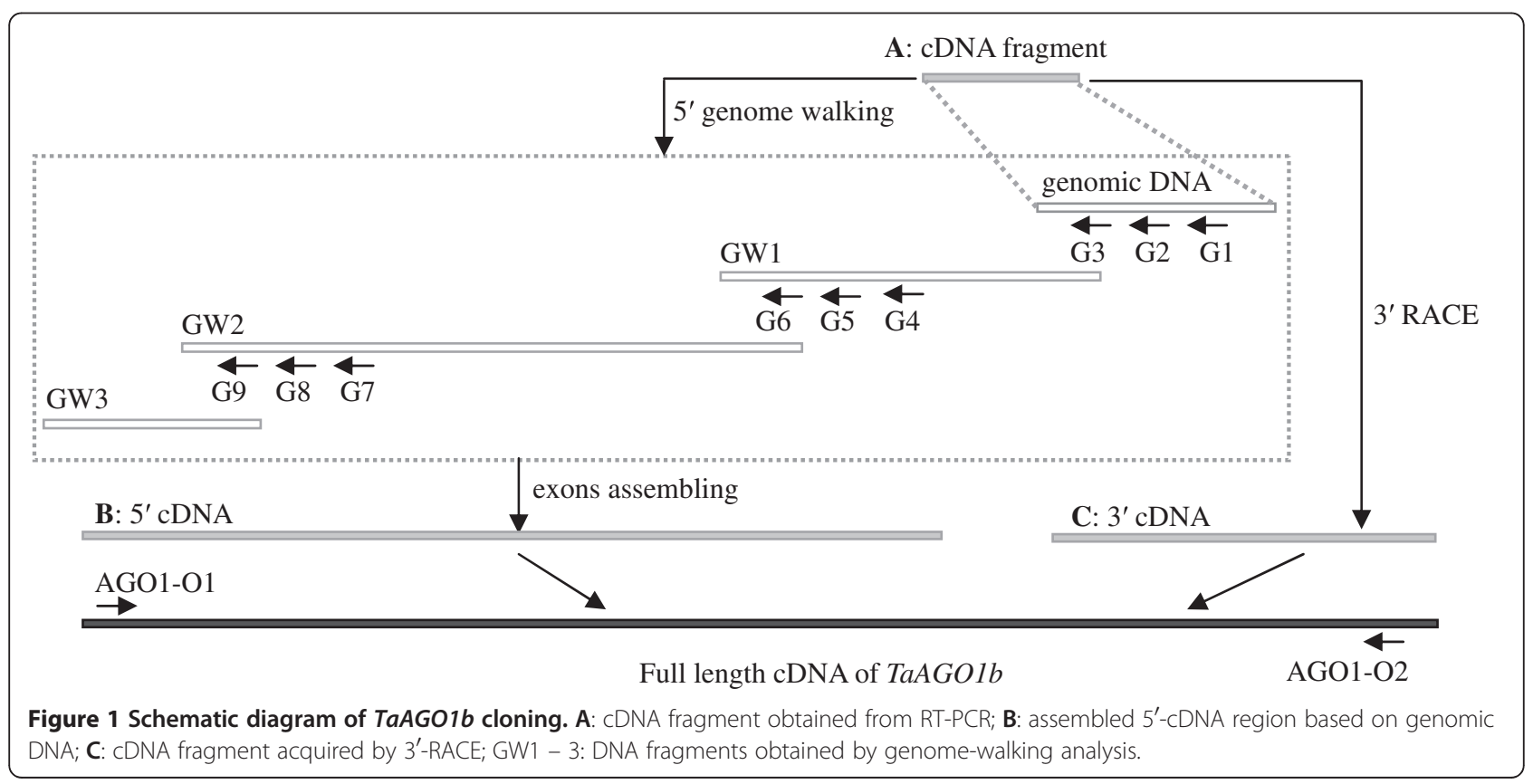


cDNA was obtained by assembling the three fragments indicated above (Figure 1-A-C), and the cDNA sequence between AGO1-O1 and -O2 was confirmed by RT-PCR cloning and sequencing. This wheat AGO gene (3273 bp long) encodes a putative protein of 868 amino acid residues, which is highly homologous to rice OsAGO1b [Swiss-Prot: Q7XSA2.3], and was designated as TaAGO1b [GenBank: JQ805149].

Using primers TaAGO4-1F and -1R, we cloned a 498bp wheat cDNA fragment via RT-PCR amplification. Sequencing results showed that this $\mathrm{CDNA}$ is very similar to Arabidopsis AGO4. Based on the cloned sequence, we obtained its full-length cDNA by 5'- and 3'-RACE. Sequence analysis indicated that the $\mathrm{CDNA}$ from our wheat AGO4 is 3157 bp long and encodes a putative protein of
916 amino acid residues. BLASTX analysis in NCBI revealed that it is highly homologous to Arabidopsis AGO4 [GenBank: AEC07929.1]. Thus, we designated it as TaAGO4 [GenBank: JQ805150].

Phylogenetic analyses of AGO plant proteins, including those from rice, Arabidopsis, and wheat, showed that TaAGO1b and TaAGO4 can be classified into two of the three groups described above (Figure 2). TaAGO1b, assigned to Group I, shares a high degree of homology with OsAGO1b, TaAGO1, OsAGO1a and AtAGO1. TaAGO4, as part of Group III, belongs to the same monophyletic subclass as rice OsAGO4a, OsAGO4b, and OsAGO6; and Arabidopsis AtAGO4, AtAGO6, AtAGO8, and AtAGO9. Three Arabidopsis AGOs (AtAGO2, 3, and 7) and two rice AGOs (OsAGO2 and 3) were sorted into Group II (Figure 2).

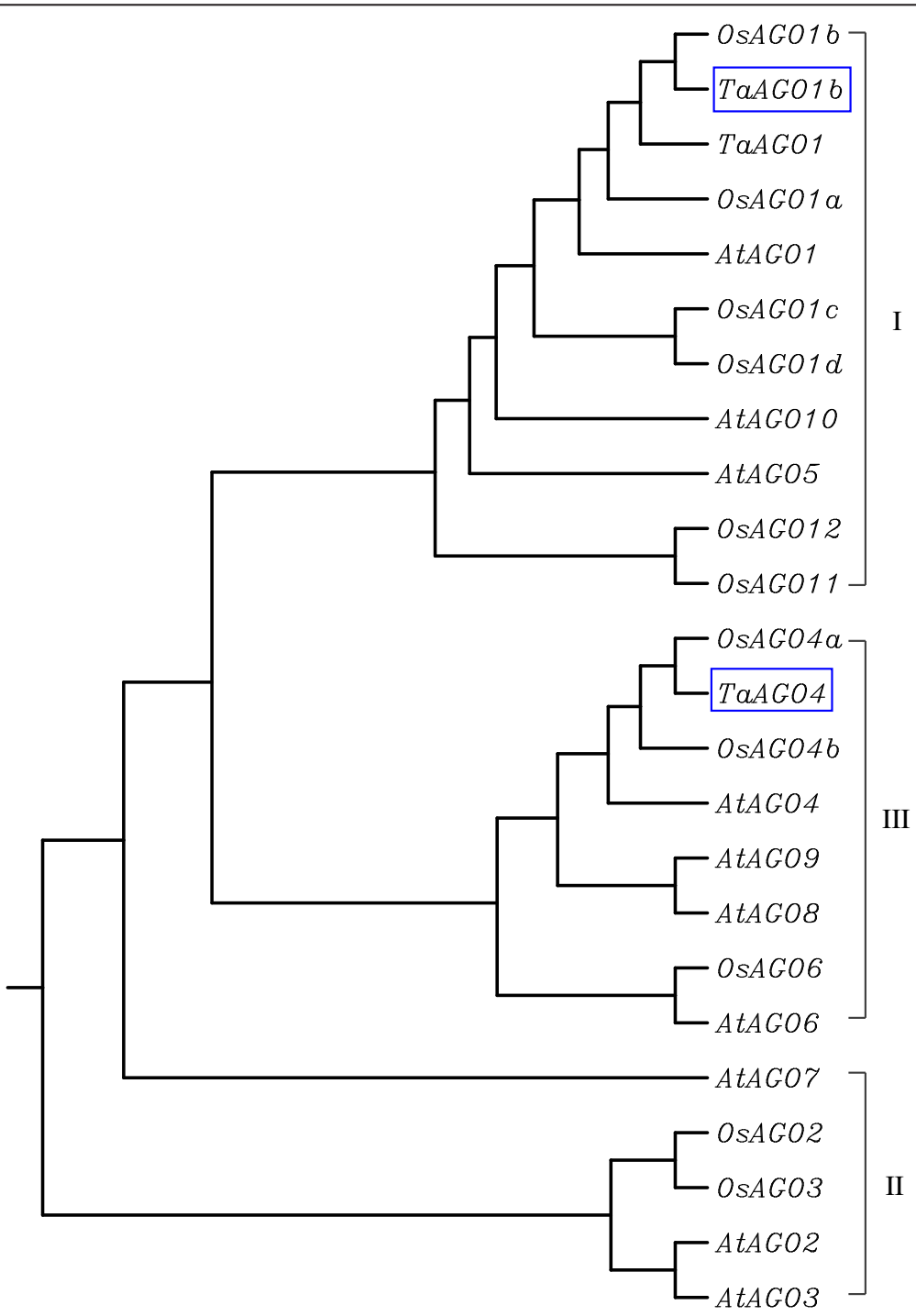

Figure 2 Phylogenetic analysis of TaAGOs and other plant AGOs. AtAGOs and OsAGOs are from Arabidopsis and rice, respectively. Three subfamilies are labeled at right margin. TaAGO1b and TaAGO4 are marked with boxes. 


\section{Characteristics of TaAGOs}

The sequence analysis at ExPaSy (http://www.expasy.org) $[13,14]$ indicated that TaAGO1b includes 868 amino acids, with a predicted molecular weight of $\sim 97.78 \mathrm{kDa}$ and theoretical pI of 9.29. TaAGO4 is 916 amino acids long and has a theoretical pI of 9.12 and a molecular mass of about $102.10 \mathrm{kDa}$.

Both TaAGOs contain typical PAZ and PIWI conserved regions (Figure 3). The PAZ domain of TaAGO1b is composed of 114 amino acids (from Residue 207 320 ) and shares 82 to $95 \%$ homology with those of AGO1 proteins in other plant species. The PAZ domain of TaAGO4 comprises 76 amino acids (Residue 325 - 400) and has only limited homology with other plant AGO4 members. The C-terminal PIWI domain of TaAGO1b includes 322 amino acids (Residue 497 - 818), and has high similarity with that domain in other plant AGO1 members, e.g., OsAGO1b (97\%), OsAGO1a (96\%), and AtAGO1 (92\%). The PIWI domain of TaAGO4 (Residue $569-875$ ) shares $90 \%, 85 \%$, and $77 \%$ homology with that of OsAGO4a, OsAGO4b, and AtAGO4, respectively. Generally, the PIWI domain displays a higher degree of similarity among plant Argonaute members, which supports a previous report of greater conservation of the PIWI domain but a poorly conserved PAZ domain [15].

When we aligned the PIWI domains of plant AGOs, including TaAGOs and paralogs in rice and Arabidopsis, we detected a trio of conserved metal-chelating amino acids aspartate, aspartate, and histidine (DDH) - in both TaAGO1b and TaAGO4 (Figure 4). These particular DDH residues play critical roles during the process of RNAdirected cleavage of target RNAs, acting as a catalytic triad [16]. Thus, the inclusion of a DDH triad in both wheat AGOs suggests that they are functionally similar to previously characterized AGOs in RNA-directed gene silencing. Previous research has shown that the conserved histidine at position 798 (H798) of AtAGO1 is essential for in vitro endonuclease activity [17]; this residue was also detected in TaAGO1b. By comparison, in TaAGO4, as well as in OsAGO4a, OsAGO4b, AtAGO6, and AtAGO8, the histidine at the 798th position was replaced by proline $(\mathrm{P})$, whereas in AtAGO4 and AtAGO9, that site was switched to serine (S) and arginine (R), respectively (Figure 4).

Structural modelling of the PIWI domain, with the Argonaute protein [PDB: 1u04] from Pyrococcus furiosus as template, indicated that TaAGOs can fold to a specific $\alpha / \beta$ structure that is dominated by a central mixed $\beta$ sheet and flanked by two long $\alpha$-helices. Here, the three aligned DDH residues (Asp, Asp, and His) were spatially close to each other and located in the "slicer" site of the PIWI domain (Figure 5).

\section{Genomic sequence analysis of TaAGO1b and TaAGO4}

The genomic DNA sequence was analyzed by DNA amplification or genome-walking, using specific primers. TaAGO1b included 20 introns that varied in length from 72 to 449 bp. By contrast, 18 introns, 78 to 858 bp long, occurred in TaAGO4 (Figure 6). The largest intron (858 bp) in TaAGO4 was located in the region corresponding to the 5' UTR of mRNA.

\section{Spatial expression patterns of TaAGOs}

Expression analysis via Semi RT-PCR demonstrated that both TaAGO1b and TaAGO4 were highly expressed in all examined tissues, including the root, stem, leaf, anther, ovule, and mature seed (Figure 7-A), as well as in developing wheat kernels (Figure 7-B). During germination, TaAGO1b and TaAGO4 were ubiquitously expressed in embryonic tissues (Figure 7-C) but only differentially expressed in the endosperm (Figure 7-D). The transcript level of TaAGO4 in the endosperm tissues of germinating wheat seeds was greatly decreased.

\section{Changes in TaAGO expression in response to vernalization}

To investigate the expression patterns of TaAGOs over time, we harvested wheat leaves at the 1- to 8-leaf stages of development and performed quantitative real-time RT-PCR. Expression of TaAGO4 was significantly upregulated in the 2- and 3-leaf stages, while that of TaAGO1b was not obviously changed during our observation period (Figure 8-A). Vernalization treatment (exposing germinated seeds to $4^{\circ} \mathrm{C}$ for $30 \mathrm{~d}$ under darkness before planting) significantly affected their expression patterns, with TaAGO4 no longer being up-regulated at the 2and 3-leaf stages but TaAGO1b being significantly upregulated at the 6- and 7-leaf stages (Figure 8-B).

For further examination of the effects of vernalization treatment, we monitored the expression of TaAGOs during cold accumulation. Both were induced in the shoot

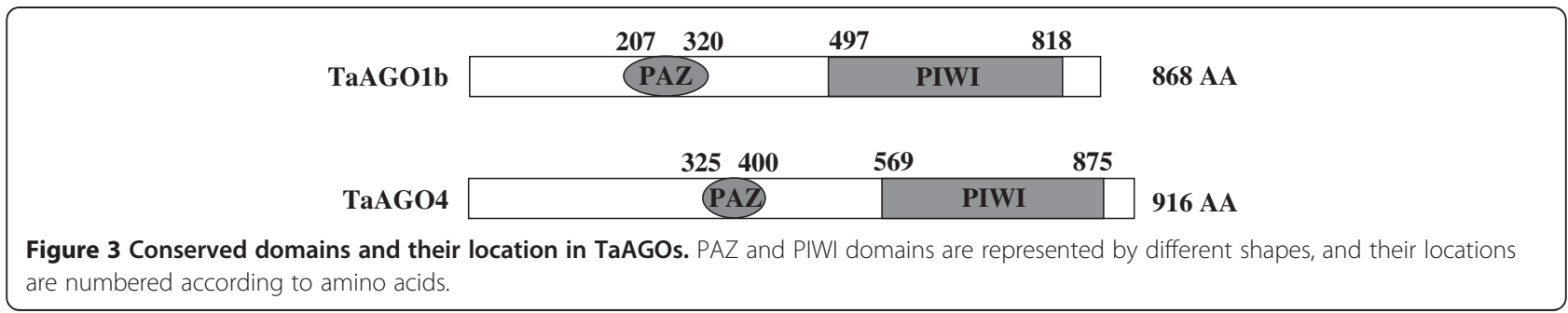


0sAG04a (605) KINAKLGGLNSLLQIET--SPSIPLVSKVPTIILGMDVSHGSPGQ-SDIPSIAAVVSSREWPLVSKYRASVRSQSPKLEMIDGLFKPQG---TaAG04 (617) KINAKLGGMNSLLQIEM--SPSIPLVSKVLTLILGMDVSHGSPGQ-SDIPSIAAVVGSREWPLVSKYRASVRSQSPKLEMIDSLFKPQ----0sAG04b (613) KINAKLGGINSLLQIEA--SPSIPLVSKTPTI ILGMDVSHGQPGQ-SDRPSIAAVVSSRQWPLISKYRASVHTQSPKLEMMSSLFKPR----AtAG04 (626) KINAKLGGLNSMLSVER--TPAFTVISKVPTI ILGMDVSHGSPGQ-SDVPSIAAVVSSREWPLISKYRASVRTQHSKAEMIESLVKKN----AtAG08 (570) KINAKLGGLNSVLDMEL--SGTMPLVMRVPTIIIGMDVSHGSPGQSDHIPSIAAVVSSREWPLISKYRACVRTQSPKVEMIDSLFKPVS---AtAG09 (598) KINAKLGGLNSLLAMER--SPAMPKVTQVPTI IVGMDVSHGSPGQ-SDIPSIAAVVSSRQWPLISKYKACVRTQSRKMEMIDNLFKPVN---AtAG06 (589) KINSKLGGINSLLGIEY--SYNIPLINKIPTLILGMDVSHGPPGR-ADVPSVAAVVGSKCWPLISRYRAAVRTQSPRLEMIDSLFQPIEN--0sAG01c (688) KINVKVGGRNTVLVDAV--SRRIPLVTDRPT I IFGADVTHPHPGE-DSSPS IAAVVASQDWPEVTKYAGLVSAQAHRQELIEDLYK IWQDPQR 0sAG01d (719) KINVKVGGRNTVLVDAV--SRRIPLVTDRPTI IFGADVTHPHPGE-DSSPS IAAVVASQDWPEVTKYAGLVSAQSHRQELIDDLYNITHDPHR 0sAG01a (759) KINVKVGGRNTVLVDAL--TRRIPLVSDRPTIIFGADVTHPHPGE-DSSPSIAAVVASQDWPEVTKYAGLVSAQAHRQELIQDLFKVWKDPQR 0sAG01b (796) KINVKVGGRNTVLVDAL--TRRIPLVSDRPTI IFGADVTHPHPGE-DSSPS IAAVVASQDWPEVTKYAGLVSAQAHRQELIQDLFKVWQDPHR TaAG01b (547) KINVRVGGRNTVLVDAL--ARRIRLVTDRPTIIFGADVTHPHPGE-DSSPSIAAVVASQDWPEITKYAGLVSAQAHRQELIQDLFKVWQDPQR AtAG01 (728) KINVKVGGRNTVLVDAL--SRRIPLVSDRPTI IFGADVTHPHPGE-DSSPSIAAVVASQDWPEITKYAGLVCAQAHRQELIQDLFKEWKDPQK TaAG01 (788) KINVKVGGRNTVLVDAL--TRRIPLVSDRPTIIFGADVTHPHPGE-DSSPSIAAVVASQDWPEVTKYAGLVGAQAHR-QEIQDLFKVWQDPQR AtAG010 (675) KINVKMGGRNTVLVDAI--SCRIPLVSDIPTI IFGADVTHPENGE-ESSPSIAAVVASQDWPEVTKYAGLVCAQAHRQELIQDLYKTWQDPVR AtAG05 (687) KINVKTGGRNTVLNDAI--RRNIPLITDRPTI IMGADVTHPQPGE-DSSPSIAAVVASMDWPEINKYRGLVSAQAHREEIIQDLYKLVQDPQR AtAG07 (698) KINAKIGGSMTELYNSIPSHIPRLLRPDEPVIFMGADVTHPHPFD-DCSPSVAAVVGSINWPEANRYVSRMRSQTHRQEI IQDLDLMVK---AtAG03 (893) KINAKVGGTNVELVDN----IFSFFKKEDKVMFIGADVNHPAAHD-NMSPS IVAVVGTLNWPEANRYAARVKAQSHRKEEIQGFGETC----AtAG02 (715) KMNAKVGGSNVELMD-----TFSFFKKEDEVMFIGADVNHPAARD-KMSPS IVAVVGTLNWPEANRYAARVIAQPHRKEEIQGFGDAC----0sAG04a $\downarrow$

(691) --AQEDDGL IRELLVDFYTSTGKRKPDQVI IFRDGVSESQFTQVLNIELDQI IEACKFLDENWSPKFTLIVAQKNHHTKFFVPGS

TaAG04 (702) --GTDDDGLVRECLIDFYTSSGKRKPDQI I IFRDGVSESQFNQVLNIELDQI IEARKFLDENWNPKFTLIVAQKNHHTKFFIPGF-

0sAG04b (698) --GTEDDGLIRESLIDFYTSSGKRKPDHVIVFRDGVSESQFTQVINIELDQI IEACKFLDEKWSPKFTVIVAQKNHHTKFFQSGS-

AtAG04 (711) --GTEDDGI I KELLVDFYTSSNKRKPEHI I IFRDGVSESQFNQVLNIELDQI IEACKLLDANWNPKFLLLVAQKNHHTKFFQPTS-

AtAG08

AtAG09

AtAG06

OsAG01c

0sAG01d

0sAG01a

0sAG01b

TaAG01b

AtAG01

TaAG01

AtAG010

AtAG05

AtAG07

AtAG03

AtAGO2

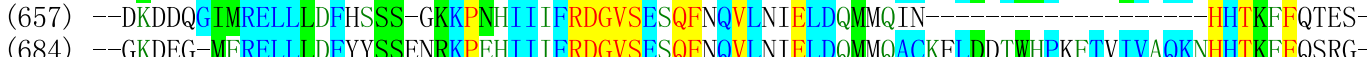

(676) -TEKGDNGIMNELFVEFYRTSRARKPKQIIIFRDGVSESQFEQVLKIEVDQIIKAYQRLGESDVPKFTVIVAQKNHHTKLFQAKG-

(778) GTVSG--GMIRELLISFKRSTG-EKPQRIIFYRDGVSEGQFYQVLLYELNAIRKACASLETNYQPKVTFIVVQKRHHTRLFAHNHNDQNSVDR (809) GPICG--GMVRELLISFKRSTG-QKPQRI IFYRDGVSEGQFYQVLLHELDAIRKACASLEANYQPQVTFIVVQKRHHTRLFAHNHNDQNSVDR (849) GTVSG--GMIRELLISFKRATG-QKPQRIIFYRDGVSEGQFYQVLFYELDAIRKACASLEADYQPPVTFVVVQKRHHTRLFANNHKDQRTVDR (886) GTVTG--GMIKELLISFKRATG-QKPQRI IFYRDGVSEGQFYQVLLYELDAIRKACASLEPNYQPPVTFVVVQKRHHTRLFANNHNDQRTVDR (637) GTVTG--GMIKELLISFKRATG-QKPQRI IFYRDGVSEGQFYQVLLFELDAIRKACASLEPNYQPPVTFVVVQKRHHTRLFANNHNDQRTVDR (818) GVVTG--GMIKELLIAFRRSTG-HKPLRIIFYRDGVSEGQFYQVLLYELDAIRKACASLEAGYQPPVTFVVVQKRHHTRLFAQNHNDRHSVDR (877) GTVTGGMETIKELLISFKRATG-QKPQRI IFYRDGVSEGQFYQVLLYELDAIRKACASLEPNYQPPVTFVVVQKRHHTRLFANNHNDQRTVDR (765) GTVSG--GMIRDLLISFRKATG-QKPLRI IFYRDGVSEGQFYQVLLYELDAIRKACASLEPNYQPPVTFIVVQKRHHTRLFANNHRDKNSTDR (777) GLVHS--GLIREHFIAFRRATG-QIPQRI IFYRDGVSEGQFSQVLLHEMTAIRKACNSLQENYVPRVTFVIVQKRHHTRLFPEQHGNRDMTDK (786) - --_---_--ELLDDFYKAVK-KLPNRI IFFRDGVSETQFKKVLQEELQSIKTACSKFQD-YNPSITFAVVQKRHHTRLFRCDP-------D (976) ---_----WE--LIEAHSQAPE-KRPNKIVIFRDGVSDGQFDMVLNVELQNVKDVFA--KVGYNPQITVIVAQKRHQTRFFPATTS--KDGRA (797) --------LE--LVKAHVQATG-KRPNKIVIFRDGVSDAQFDMVLNVELLDVKLTFE--KNGYNPKITVIVAQKRHQTRFFPATN---NDGSD

0sAG04a (774) QNNVPPGTVVDNAVCHPRNNDFYMCAHAGMIGTTRPTHYHILHDEIGFSADDLQELVHSLSYVYQRSTTAISVVAPICYAHLAAAQVSQFIK

TaAG04 (785) PDNVPPGTVVDNAVCHPRNYDFYMCAHAGMIGTTRPTHYHILHDEIHFAADDLQDLVHSLSYVYQRSTTAISVVSPICYAHLAAAQVAQFIK (781) PDNVPPGTVVDKQVCHPRNYDFYMCAHAGMIGTTRPTHYHVLHDEIGFSPDDLQELVHSLSYVYQRSTTAISVVAPICYAHLAAAQVGTFLK (794) PENVPPGTIIDNKICHPKNNDFYLCAHAGMIGTTRPTHYHVLYDEIGFSADELQELVHSLSYVYQRSTSAISVVAPICYAHLAAAQLGTFMK (720) PNNVLPGTIIDSNICHQHNNDFYLCAHAGKIGTTRPTHYHVLYDEIGFDTDQLQELVHSLSYVYQRSTTAISLVAPICYAHLAAAQMATAMK (766) PDNVPPGT IIDSQICHPRNFDFYLCAHAGMIGTTRPTHYHVLYDEIGFATDDLQELVHSLSYVYQRSTTAISVVAPVCYAHLAAAQMGTVMK (760) PENVPAGTVVDTKIVHPTNYDFYMCAHAGKIGTSRPAHYHVLLDEIGFSPDDLQNLIHSLSYVNQRSTTATSIVAPVRYAHLAAAQVAQFTK (868) SGNILPGTVVDSKICHPTEFDFYLCSHAGIKGTSRPAHYHVLWDENNFTADALQILTNNLCYTYARCTRSVSIVPPAYYAHLAAFRARFYME (899) SGNILPGTVVDSKICHPTEFDFFLCSHAGIKGTSRPAHYHVLWDENNFTADALQTLTNNLCYTYARCTRSVSIVPPAYYAHLAAFRARFYME (939) SGNILPGTVVDSKICHPTEFDFYLCSHAGIQGTSRPAHYHVLWDENKFTADGLQTLTNNLCYTYARCTRSVSIVPPAYYAHLAAFRARFYME (976) SGNILPGTVVDSKICHPTEFDFYLCSHAGIQGTSRPAHYHVLWDENKFTADELQTLTNNLCYTYARCTRSVSIVPPAYYAHLAAFRARFYME (727) SGNILPGTVVDSKICHPTEFDFYLCSHAGIQGTSRPAHYHVLWDENKFTADELQTLTNNLCYTYARCTRSVSIVPPAYYAHLAAFRARFYME (908) SGNILPGTVVDSKICHPTEFDFYLCSHAGIQGTSRPAHYHVLWDENNFTADGLQSLTNNLCYTYARCTRSVSIVPPAYYAHLAAFRARFYME (969) SGNILPGTVVDSKICHPTEFDFYLCSHAGIQGTSRPAHYHVLWDENKFTADELQTLTNNLCYTYARCTRSVSIVPPAYYAHLAAFRARFYME (855) SGNILPGTVVDTKICHPTEFDFYLCSHAGIQGTSRPAHYHVLWDENNFTADGIQSLTNNLCYTYARCTRSVSIVPPAYYAHLAAFRARFYLE (867) SGNIQPGTVVDTKICHPNEFDFYLNSHAGIQGTSRPAHYHVLLDENGFTADQLQMLTNNLCYTYARCTKSVSIVPPAYYAHLAAFRARYYME (859) HENIPPGTVVDTVITHPKEFDFYLCSHLGVKGTSRPTHYHILWDENEFTSDELQRLVYNLCYTFVRCTKPISIVPPAYYAHLAAYRGRLYIE (1054) KGNVPSGTVVDTTIIHPFEYDFYLCSQHGAIGTSKPTHYYVLSDEIGFNSNQIQKLIFDLCFTFTRCTKPVALVPPVSYADKAASRGRVYYE (874) KGNVPSGTVVDTKVIHPYEYDFYLCSHHGGIGTSKPTHYYTLWDELGFTSDQVQKL IFEMCFTFTRCTKPVSLVPPVYYADMVAFRGRMYHE

Figure 4 Alignment of PIWI domains in plant AGOs. Conserved Asp, Asp, and His (DDH) triad residues are marked with downward arrows. The H798 site of AtAGO1 is indicated by box. Amino acid positions for each PIWI domain are numbered. 

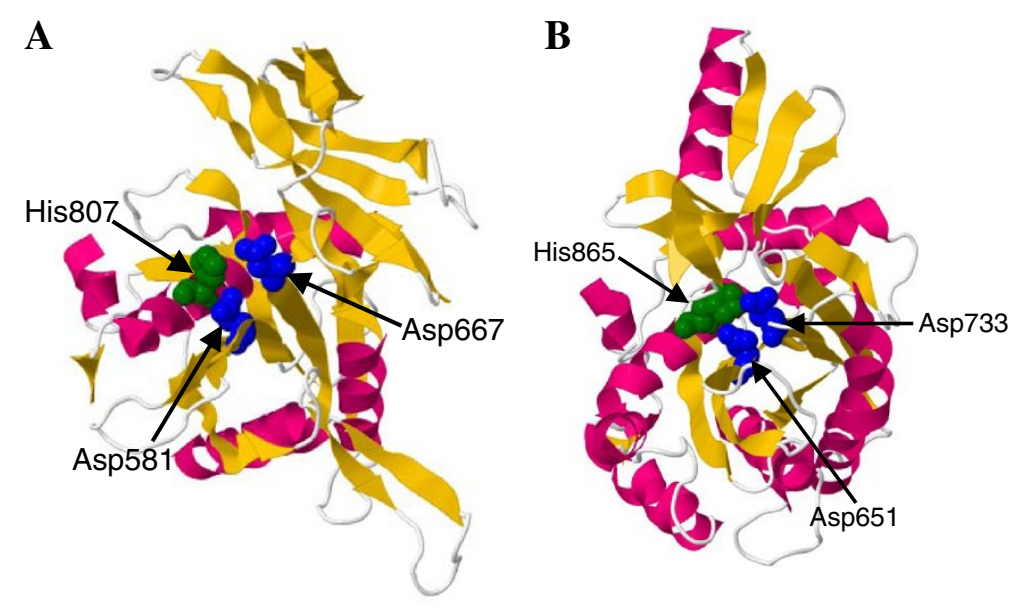

Figure 5 Structural models of PIWI domains in TaAGO1b (A) and TaAGO4 (B). DDH catalytic triad is colored blue for Asp (D) and green for His $(H)$.

tissues, with expression of TaAGO4 being greatly upregulated at 18 to $30 \mathrm{~d}$ after cold treatment began but induction of TaAGO1b being relatively lower (Figure 8-C). However, no obvious induction of TaAGOs was detected in root tissues during the cold accumulation (Figure 8-D). These results indicated that both genes have important roles within the vernalization response, but their functioning might involve different regulatory mechanisms.

\section{In silico mapping of TaAGOs}

From a set of wheat aneuploids and deletion stocks, over 16000 ESTs have been mapped in the wheat chromosome / chromosome bins [18]. Those results are very useful for in silico mapping analysis. Through BLASTN searches, we identified mapped ESTs that are homologous to wheat AGO genes (Additional file 2). Based on sequence similarities and positions, we were able to map TAGO1 to the long arm of 7D and TaAGO4 to the short arm of 3A, 3B, and $3 \mathrm{D}$ on the wheat chromosomes.

\section{Discussion}

Regulation of gene expression at the post-transcriptional level plays a critical role in plant development. RNAi pathways are involved in post-transcriptional gene silencing and chromatin modifications. Argonaute proteins comprise a highly conserved family whose members have been implicated in RNAi- and related pathways in plants [15]. We isolated two wheat AGO genes with full-length cDNA, TaAGO1b and TaAGO4. Both TaAGOs are basic proteins (pI 9.0) with predicted molecular weights of $\sim 100 \mathrm{kDa}$ that are similar to other AGO members in eukaryotes $[6,19]$. Argonautes are characterized by two highly conserved domains, PAZ and PIWI, that have important roles during the processes of RNAi-mediated gene regulation [4]. The PAZ domain is a key region that interacts with the 3 ' end of small RNAs and determines the RNA-binding specificity of Argonautes. The PIWI domain binds to the $5^{\prime}$ end and also interacts with the target RNA [5]. Among rice AGOs, homology of PAZ domains is relatively lower $(\sim 21 \%)$, whereas the PIWI domains are highly conserved and show homologies of $>90 \%$ [16]. We also found that the PIWI domain of AGOs is highly conserved among Arabidopsis, rice, and wheat. That domain exhibits extensive homology to RNase $\mathrm{H}$; some Argonaute proteins cleave the target RNAs that have sequences complementary to the small RNAs [17]. During this process of sequencespecific cleavage, three conserved metal-chelating residues in the PIWI domain play critical roles and function as a catalytic triad $[16,20]$. In addition, PIWI proteins with degenerate active catalytic motifs of ' $D-D-H / D / E / K$ ' show

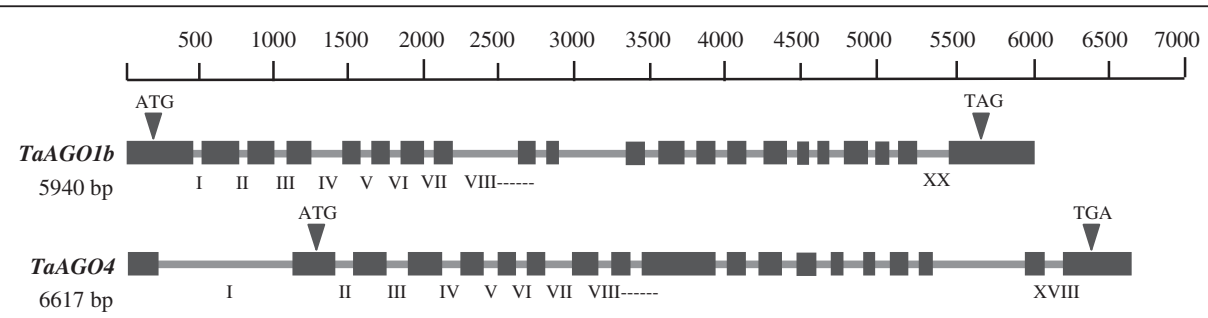

Figure 6 Genomic characterization of TaAGO1b and TaAGO4. Black boxes indicate exons; translational start and stop codons are shown. 


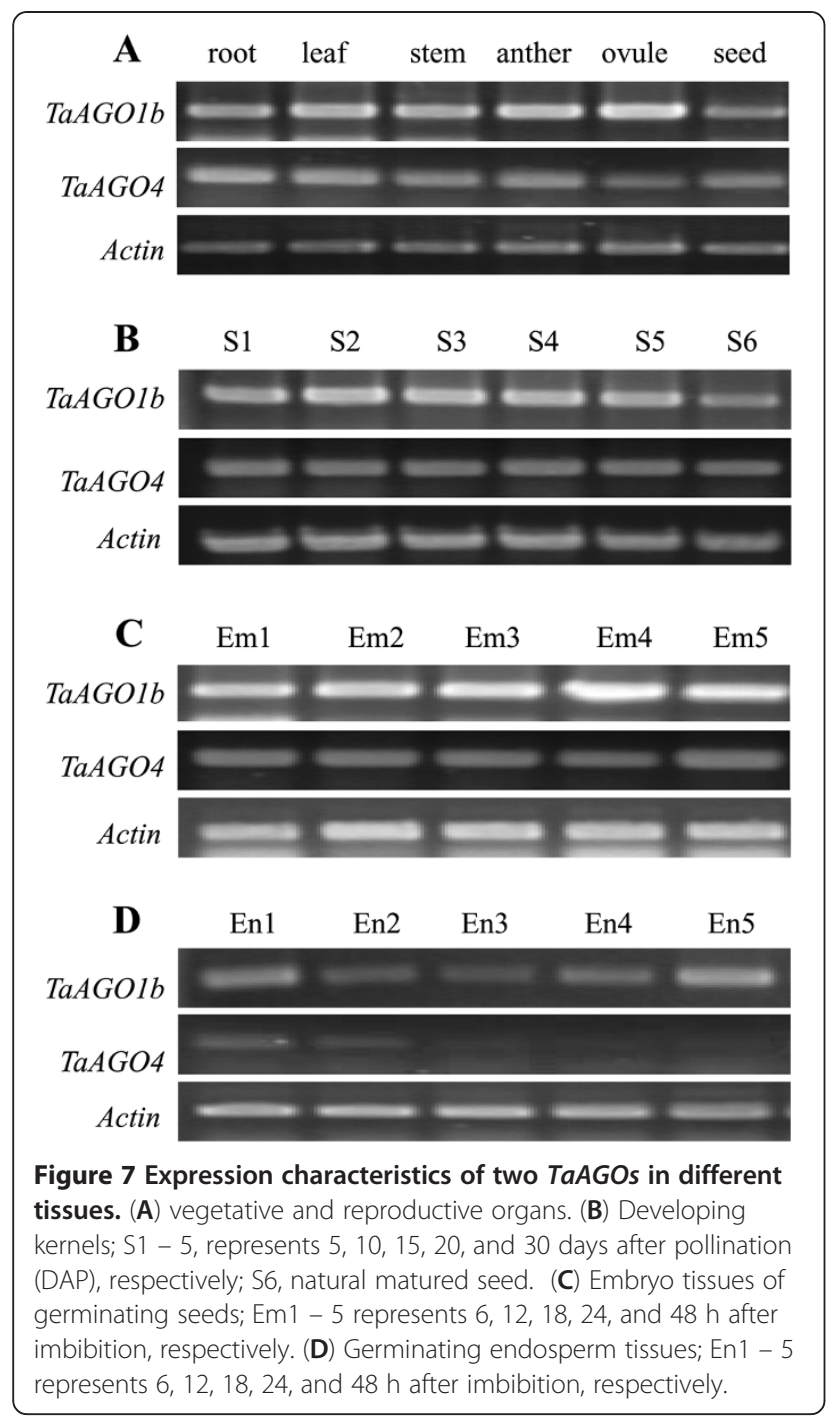

deduced slicer or slicer-like activity [6]. We detected this conserved DDH triad in both TaAGO1b and TaAGO4. Structural modelling indicated that the DDH residues were spatially close to each other and located at the "slicer" site of the PIWI domains. These features demonstrate the regulatory functioning of TaAGOs within the RNAi machinery.

In plants, RNAi-dependent pathways have been widely implicated in the control of gene expression and involvement in various developmental events [21,22]. Components of the RNAi machinery participate in the maintenance of undifferentiated cells in the shoot apical meristem (SAM), initiation of lateral organ primordia from SAM and floral meristems, and the formation of male and female germ cells [11,23,24]. In Arabidopsis, AGO1 and AGO10 regulate the termination of floral stem cells through two microRNAs, miR172 and miR165/166 [10]. In rice, microarraybased expression profiling has shown that the counterparts of Arabidopsis AGO1 and AGO4 are significantly upregulated at the onset of floral development [16]. In our

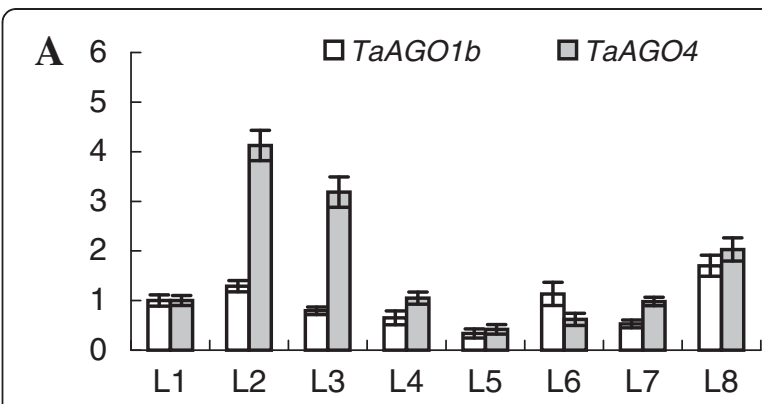

B

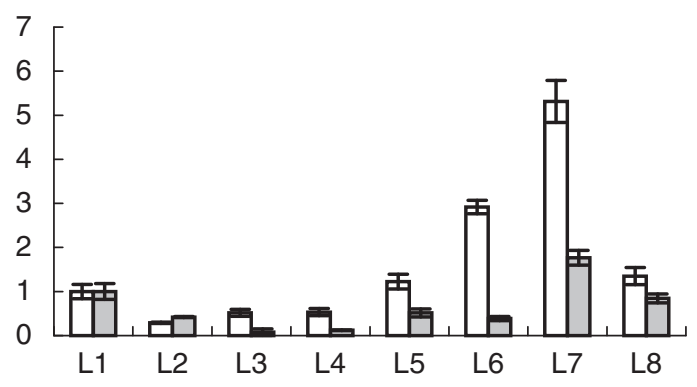

C 1

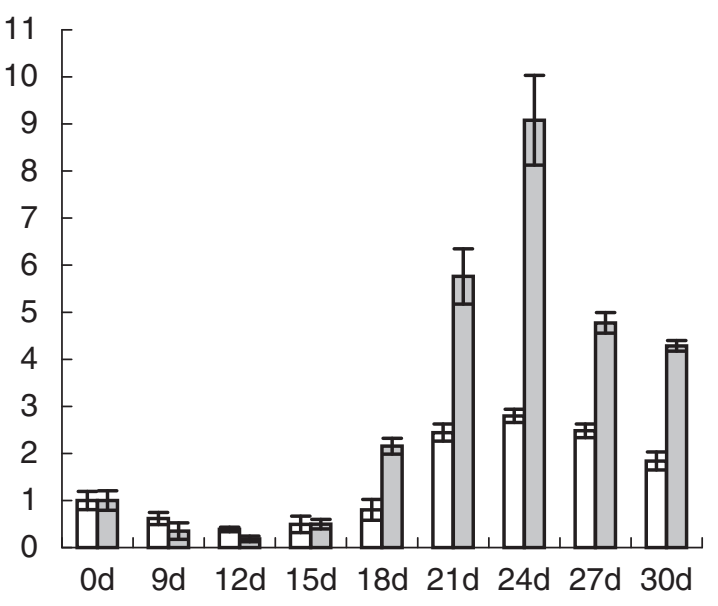

D 6

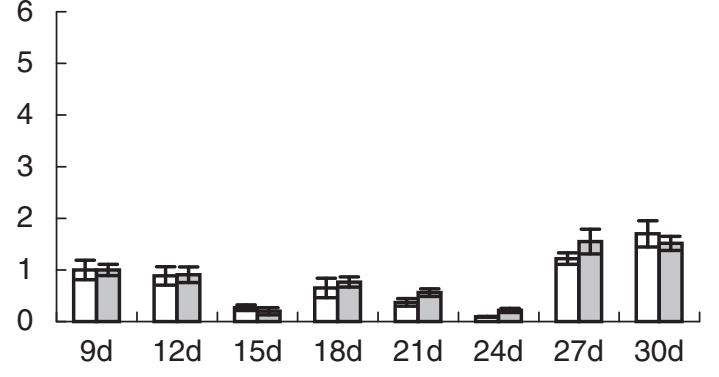

Figure 8 Expression of TaAGOs during wheat plant development and vernalization. (A) Wheat plants without vernalization treatment; $L 1-8,1$ - to 8-leaf stages. (B) Wheat plants vernalized at germinating stage (exposed germinated seeds to $4^{\circ} \mathrm{C}$ for $30 \mathrm{~d}$ under darkness before planting). (C) Shoot tissues during vernalization treatment; $0-30 \mathrm{~d}$, cold $\left(4^{\circ} \mathrm{C}\right)$ treatment for 0 to $30 \mathrm{~d}$, respectively. (D) Root tissues during vernalization. 
study, TaAGO1b and TaAGO4 were ubiquitously expressed in both vegetative and reproductive organs, but differentially expressed in germinating endosperm tissues. Expression of TaAGO4 was immediately and greatly decreased in those endosperm tissues after seed imbibition, suggesting that TaAGO4 is involved in the RNA-directed silencing of certain target genes in the endosperm (such as those that encode amylases). Moreover, this down-regulation of TaAGO4 was consistent with the up-regulation of enzymes during germination, which are necessary for breaking down endosperm starch into sugars to nourish the growing seedlings.

We were also interested to find that TaAGO4 was significantly up-regulated in leaves at the 2- and 3-leaf stages, and that this expression pattern was also significantly affected by vernalization treatment. However, neither TaAGO1b nor TaAGO4 was induced by treatment at $4^{\circ} \mathrm{C}$ for $15 \mathrm{~d}$. Nevertheless, after $21 \mathrm{~d}$ of cold accumulation, both were significantly up-regulated. This suggested that TaAGO1b and TaAGO4 are involved in the RNA-directed silencing of certain flowering repressors in shoots during wheat vernalization. In root tissues, no obvious induction of TaAGOs was detected under cold stress, a finding consistent with previous reports that TaAGO1 (a homolog of TaAGO1b) is not responsive to low-temperature stress, but is significantly regulated by dehydration [25]. Thus, our results indicate potential involvement by TaAGO1b and TaAGO4 in developmentspecific gene regulatory mechanisms. This provides insight into probable functions for TaAGOs and serves as a new starting point for further investigations aimed at understanding RNAi-dependent gene regulation during seed germination and vernalization in wheat.

\section{Conclusions}

Argonaute proteins are key components of RNA-directed gene silencing, playing important roles in the regulation of plant development. We cloned and characterized two Argonaute genes from wheat, $\mathrm{TaAGO} 1 \mathrm{~b}$ and TaAGO4. Our results suggested they encode functional AGO proteins. Interestingly, these two genes manifested different patterns of expression during seed germination and plant growth, as well as in response to vernalization treatment. This demonstrates that TaAGO1b and TaAGO4 are probably involved in the developmental regulation of wheat plants.

\section{Methods}

\section{Plant sample preparation}

The roots, stems, leaves, anthers, ovules, and mature seeds were sampled from a winter wheat cultivar, 'Jing 841'. Developing seeds were collected at 5, 10, 15, 20, and 30 DAP from field-grown plants. For germination treatment, mature seeds were surface-sterilized in 5\% sodium hypochloride for $15 \mathrm{~min}$ and washed four times (2 min each) with sterilized water. They then imbibed water from moist filter paper in Petri dishes in a temperaturecontrolled cultivation chamber (16-h photoperiod at $25^{\circ} \mathrm{C}$ ). Embryo and endosperm tissues were isolated at 6, 12, 24, 48 , and $72 \mathrm{~h}$ after imbibition.

To monitor the expression of wheat AGOs over time, we placed seeds in pots and cultured them in a temperaturecontrolled chamber at $25^{\circ} \mathrm{C}$ and under a $16-\mathrm{h}$ photoperiod. Leaves were harvested at the 1- to 8-leaf stages.

For studying the effects of vernalization treatment on AGO expression, seeds imbibed water for $24 \mathrm{~h}$ and were then transferred for $30 \mathrm{~d}$ to a cold chamber $\left(4^{\circ} \mathrm{C}\right.$ in the dark). After vernalization, they were planted in pots and cultured in a temperature-controlled chamber at $25^{\circ} \mathrm{C}$ and under a 16-h photoperiod. Leaves were harvested at the 1- to 8-leaf stages. To examine the expression patterns of AGOs during this vernalization treatment, we sampled shoot and root tissues on Days $0,9,12,15,18$, $21,24,27$, and 30 . All materials were prepared from three replicates of each independent treatment.

\section{Preparation of total RNA and genomic DNA}

Total RNA was extracted as previously described [26], and the integrity of those samples was assessed by agarose gel $(0.8 \%)$ electrophoresis. The concentration and purity of RNA were determined from the A260/A280 ratio, using a UC800 nucleic acid-protein analyzer (Beckman Co., USA). Genomic DNA was extracted from the wheat leaves according to the CTAB (hexadecyltrimethylammonium bromide) method [27].

\section{Cloning of CDNAs}

Two Arabidopsis Argonaute genes, AGO1 [GenBank: NM_179453] and AGO4 [GenBank: NM_128262], were used in our TBLASTX search against the EST database. From this, we identified two groups of wheat EST sequences - GenBank CF133307, CA741561, CK155094, CJ900837, CA726349, and BE586111; and GenBank BT009411, BQ841772, HX190168, CB307539, BJ244578, and CJ679989, which are highly homologous to AGO1 and $A G O 4$, respectively. Based on the conserved regions in each of the wheat groups, we designed primer pairs TaAGO1-1F/1R and TaAGO4-1F/1R (Additional file 1) for use in cDNA cloning of the wheat genes. RT-PCR was conducted with $2 \mu \mathrm{l}$ of cDNA as template plus 125 pmol of each primer in a $20-\mu \mathrm{l}$ reaction system that contained $0.2 \mathrm{mM}$ of each dNTP, $1.5 \mathrm{mM} \mathrm{MgCl}_{2}$, and $1 \mathrm{U}$ of Taq polymerase. The PCR program was as follows: 5 min at $94^{\circ} \mathrm{C}$; then 40 cycles of $1 \mathrm{~min}$ at $95^{\circ} \mathrm{C}, 1 \mathrm{~min}$ at $53^{\circ} \mathrm{C}$, and $1 \mathrm{~min}$ at $72^{\circ} \mathrm{C}$; plus a final extension of 10 $\min$ at $72^{\circ} \mathrm{C}$. After the products were separated by $1 \%$ agarose gel electrophoresis, their bands were recovered and sub-cloned into the pBS-T vector (TakaRa, China) for sequencing. The RACE technique was performed 
with a TaKaRa kit (5'-Full RACE Kit and 3'-Full RACE Core Set Ver. 2.0) according to the manufacturer's instructions. Specific primers are listed in Additional file 1. The gene-specific primer GP1 was combined with the outer primer of 3'-RACE, while GP3 was combined with that of $5^{\prime}$-RACE. Specific primers GP2 and GP4 were combined with $3^{\prime}$ - and $5^{\prime}$ - RACE inner primers, respectively.

\section{Confirmation of full-length cDNAs}

To verify the assembled sequences, we designed genespecific primers and sequenced the RT-PCR products. Primers TaAGO1-O1 and TaAGO1-O2 were used to clone TaAGO1b, while TaAGO4-O1 and TaAGO4-O2 were used for TaAGO4 amplification (Additional file 1).

\section{Genomic characterization of TaAGOs}

We used specific primers in genomic DNA amplification to analyze the genomic sequence of TaAGO1b. Primers TaAGO1-1F/R and TaAGO1-2F/R were applied in cloning the 3 '-region whereas the $5^{\prime}$-region was amplified with a genome-walking kit (Takara, Japan). Those genomewalking primers (TaAGO1-G1 through TaAGO1-G9) are listed in Additional file 1 and their locations are shown in Figure 1. Six pairs of gene-specific primers (AGO4-1F/R through AGO4-6F/R) were used for genomic DNA amplification of TaAGO4.

\section{Gene sequence analysis and in silico mapping}

A BLAST search was performed at NCBI. The amino acid sequence was deduced and its structure predicted at ExPaSy $[13,14]$. ClustalW (http://www.ebi.ac.uk/clustalw/) was used for alignment and phylogenetic analysis. A structural model of the PIWI domain was constructed with the HHpred server, using Modeller 8.0 [28]. The selected template structure (i.e., the best hit from HHpred) was that of the P. furiosus Argonaute protein (PfAGO; UniProt code: Q8U3D2, PDB id 1U04) [19]. The model of the PIWI domain included Residues 825 to 1070. In silico mapping on the Chinese Spring deletion map was conducted at Graingenes (http://wheat.pw.usda.gov/GG2/blast.shtml).

\section{Gene expression analysis}

Gene-specific primer pairs AGO1-F/R and AGO4-1F/R were used for RT-PCR analysis, and the actin gene [GenBank: AB181991] served as the endogenous control. Primers included TaAc-F: GTTCCAATCTATGAG GGATACACGC and TaAc-R: GAACCTCCACTGAGA ACAACATTACC. RT-PCR was carried out with $2 \mu \mathrm{l}$ of cDNA as template and 125 pmol of each primer in a $20-\mu \mathrm{l}$ reaction system that contained $0.2 \mathrm{mM}$ of each dNTP, $1.5 \mathrm{mM} \mathrm{MgCl}_{2}$, and $1 \mathrm{U}$ of Taq polymerase. The PCR program was as follows: $5 \mathrm{~min}$ at $94^{\circ} \mathrm{C}$; then 28 cycles of $1 \mathrm{~min}$ at $95^{\circ} \mathrm{C}, 1 \mathrm{~min}$ at $53^{\circ} \mathrm{C}$, and $1 \mathrm{~min}$ at $72^{\circ} \mathrm{C}$; plus a final extension of $10 \mathrm{~min}$ at $72^{\circ} \mathrm{C}$. The products were separated by $1 \%$ agarose gel electrophoresis. Realtime quantitative RT-PCR was performed as previously described [26], with the ubiquitin gene (GenBank Accession No: AY297059) used as the endogenous control. Primers included UF: ATCCAGGACAAGGAGGGCA and UR: CGGAGACGGAGCACCAAG. All other primers are listed in Additional file 1.

\section{Additional files}

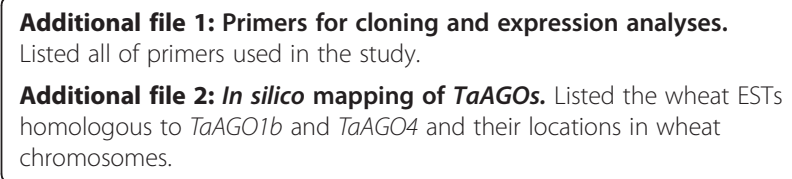

\section{Abbreviations}

AGO: Argonaute; CTAB: Hexadecyltrimethylammonium bromide; DAP: Days after pollination; EST: Expressed sequence tag; PAZ: Piwi Argonaute and Zwille; PIWI: P-element induced wimpy testis; RACE: Rapid Amplification of CDNA Ends; RNAi: RNA interference; RT-PCR: Reverse transcription-polymerase chain reaction.

\section{Competing interests}

The authors declare that they have no competing interests.

\section{Authors' contributions}

FM performed the bioinformatics, gene-cloning, and phylogenetic analyses. $H J, N L, Y X$, and $H L$ were involved in the gene-cloning and expression assays. KW participated in the bioinformatics analysis. FM, JY, and YL designed and prepared the manuscript. All authors read and approved the final manuscript.

\section{Acknowledgements}

This work was financially supported by the National Natural Science Foundation of China (31071410 and 30971771).

\section{Author details}

${ }^{1}$ College of Life Science, Henan Agricultural University, Zhengzhou 450002, China. ${ }^{2}$ National Engineering Research Centre for Wheat, Henan Agricultural University, Zhengzhou 450002, China. ${ }^{3}$ State Key Laboratory Cultivation Base of Crop Physiological Ecology and Genetic Improvement in Henan Province, Henan Agricultural University, Zhengzhou 450002, China.

Received: 16 October 2012 Accepted: 31 January 2013 Published: 4 February 2013

\section{References}

1. Rivas FV, Tolia NH, Song JJ, Aragon JP, Liu J, Hannon GJ, Joshua-Tor L: Purified Argonaute2 and an siRNA form recombinant human RISC. Nat Struct Mol Biol 2005, 12(4):340-349.

2. Baulcombe D: RNA silencing in plants. Nature 2004, 431(7006):356-363.

3. Bohmert K, Camus I, Bellini C, Bouchez D, Caboche M, Benning C: AGO1 defines a novel locus of Arabidopsis controlling leaf development. $E M B O$ J 1998, 17(1):170-180.

4. Vaucheret H: Plant ARGONAUTES. Trends Plant Sci 2008, 13(7):350-358.

5. Hutvagner G, Simard MJ: Argonaute proteins: key players in RNA silencing. Nat Rev Mol Cell Biol 2008, 9(1):22-32.

6. Tolia NH, Joshua-Tor L: Slicer and the argonautes. Nat Chem Biol 2007, 3(1):36-43.

7. Yigit E, Batista PJ, Bei Y, Pang KM, Chen CC, Tolia NH, Joshua-Tor L, Mitani S, Simard MJ, Mello CC: Analysis of the C. elegans Argonaute family reveals that distinct Argonautes act sequentially during RNAi. Cell 2006, 127(4):747-757.

8. Cenik ES, Zamore PD: Argonaute proteins. Curr Biol 2011, 21(12):R446-449.

9. Carbonell A, Fahlgren N, Garcia-Ruiz H, Gilbert KB, Montgomery TA, Nguyen T, Cuperus JT, Carrington JC: Functional analysis of three Arabidopsis 
Argonautes using slicer-defective mutants. Plant Cell 2012, 24(9):3613-3629.

10. Ji L, Liu X, Yan J, Wang W, Yumul RE, Kim YJ, Dinh TT, Liu J, Cui X, Zheng B, et al: ARGONAUTE10 and ARGONAUTE1 regulate the termination of floral stem cells through two microRNAs in Arabidopsis. PLoS Genet 2011, 7(3):e1001358

11. Nonomura K, Morohoshi A, Nakano M, Eiguchi M, Miyao A, Hirochika H, Kurata N: A germ cell specific gene of the ARGONAUTE family is essential for the progression of premeiotic mitosis and meiosis during sporogenesis in rice. Plant Cell 2007, 19(8):2583-2594.

12. Brenchley R, Spannagl M, Pfeifer M, Barker GLA, D'Amore R, Allen AM, McKenzie N, Kramer M, Kerhornou A, Bolser D, et al: Analysis of the bread wheat genome using whole-genome shotgun sequencing. Nature 2012, 491(7426):705-710.

13. Arnold K, Bordoli L, Kopp J, Schwede T: The SWISS-MODEL workspace: a web-based environment for protein structure homology modelling. Bioinformatics 2006, 22(2):195-201.

14. Bordoli L, Kiefer F, Arnold K, Benkert P, Battey J, Schwede T: Protein structure homology modeling using SWISS-MODEL workspace. Nat Protoc 2009, 4(1):1-13.

15. Carmell MA, Xuan Z, Zhang MQ, Hannon GJ: The Argonaute family: tentacles that reach into RNAi, developmental control, stem cell maintenance, and tumorigenesis. Genes Dev 2002, 16(21):2733-2742.

16. Kapoor M, Arora R, Lama T, Nijhawan A, Khurana JP, Tyagi AK, Kapoor S: Genome-wide identification, organization and phylogenetic analysis of Dicer-like, Argonaute and RNA-dependent RNA Polymerase gene families and their expression analysis during reproductive development and stress in rice. BMC Genomics 2008, 9:451.

17. Baumberger N, Baulcombe DC: Arabidopsis ARGONAUTE1 is an RNA Slicer that selectively recruits microRNAs and short interfering RNAs. Proc Natl Acad Sci USA 2005, 102(33):11928-11933.

18. Lazo GR, Chao S, Hummel DD, Edwards H, Crossman CC, Lui N, Matthews DE, Carollo VL, Hane DL, You FM, et al: Development of an expressed sequence tag (EST) resource for wheat (Triticum aestivum L.): EST generation, unigene analysis, probe selection and bioinformatics for a 16,000-locus bin-delineated map. Genetics 2004, 168(2):585--593.

19. Song JJ, Smith SK, Hannon GJ, Joshua-Tor L: Crystal structure of Argonaute and its implications for RISC slicer activity. Science 2004, 305(5689):1434-1437.

20. Parker JS, Roe SM, Barford D: Structural insights into mRNA recognition from a PIWI domain-siRNA guide complex. Nature 2005, 434(7033):663-666.

21. Chen X: A microRNA as a translational repressor of APETALA2 in Arabidopsis flower development. Science 2004, 303(5666):2022-2025.

22. Hamilton AJ, Baulcombe DC: A species of small antisense RNA in posttranscriptional gene silencing in plants. Science 1999, 286(5441):950-952.

23. Nagasaki H, Itoh J, Hayashi K, Hibara K, Satoh-Nagasawa N, Nosaka M, Mukouhata M, Ashikari M, Kitano H, Matsuoka M, et al: The small interfering RNA production pathway is required for shoot meristem initiation in rice. Proc Natl Acad Sci USA 2007, 104(37):14867-14871.

24. Liu B, Li P, Li X, Liu C, Cao S, Chu C, Cao X: Loss of function of OsDCL1 affects microRNA accumulation and causes developmental defects in rice. Plant Physiol 2005, 139(1):296-305.

25. Liu T, Li J, Gu J, Lu W, Guo C, Li R, Xiao K: Cloning and molecular characterization of TaAGO1, a member of argonaute gene family in wheat (Triticum aestivum L.). Afric J Biotechnol 2011, 10(62):13407-13417.

26. Li Y, Meng F, Yin J, Liu H, Si Z, Ni Z, Sun Q, Ren J, Niu H: Isolation and comparative expression analysis of six MBD genes in wheat. Biochim Biophys Acta 2008, 1779(2):90-98.

27. Saghai-Maroof MA, Soliman KM, Jorgensen RA, Allard RW: Ribosomal DNA spacer-length polymorphisms in barley: mendelian inheritance, chromosomal location, and population dynamics. Proc Natl Acad Sci USA 1984, 81(24):8014-8018.

28. Eswar N, Webb B, Marti-Renom MA, Madhusudhan MS, Eramian D, Shen MY, Pieper U, Sali A, Eswar N, Webb B, Marti-Renom MA, Madhusudhan MS, Eramian D, Shen MY, Pieper U, Sali A: Comparative protein structure modeling using MODELLER. Curr Protoc Protein Sci 2007, 2:2-9.

\section{Submit your next manuscript to BioMed Central and take full advantage of:}

- Convenient online submission

- Thorough peer review

- No space constraints or color figure charges

- Immediate publication on acceptance

- Inclusion in PubMed, CAS, Scopus and Google Scholar

- Research which is freely available for redistribution 